\title{
Labour relations and working conditions. Determinants using macroeconomic indicators: A quantitative research
}

\author{
Nickolaos Efstratios Giovanis ${ }^{1, ~}$, George Asterios Drogalas ${ }^{2}$ \\ ${ }^{1}$ Department of Business Administration, Technological Educational Institute Of Central Macedonia, Macedonia, Greece \\ ${ }^{2}$ Department of Marketing \& Operation Management, University of Macedonia, Thessaloniki, Greece
}

Email address:

ng@teiser.gr (N. E. Giovanis), georgedrogalas@yahoo.gr (G. A. Drogalas)

\section{To site this article:}

Nickolaos Efstratios Giovanis, George Asterios Drogalas. Labor Relations and Working Conditions. Determinants using Macroeconomic Indicators: A Quantitative Research. Journal of Human Resource Management. Vol. 2, No. 1, 2014, pp. 1-8.

doi: $10.11648 /$ j.jhrm.20140201.11

\begin{abstract}
The era in which we live is characterized by rapid technological, economic and social developments, which imply rapid changes in ways of work, labour relations and the overall quality of life of individuals. On the other hand, the object of labour relations is closely connected with the study of the factors that affect the organisation and functioning of organisations. The organisational aspects of work are usually expressed through the framework of working conditions. One of the parameters of working conditions is occupational accidents, which are an unavoidable fact - because of the continual economic activity of man - and create a large number of problems. Their economic impact is felt through the reduction of production and productivity, and the increase of costs and pensions benefits. From a social point of view, occupational accidents or, even more, the death of an employee, are more devastating in the general social environment. This paper presents the results of a quantitative research conducted using multiple regression and shows that there is a relation between fatal injuries and various macroeconomics measures or other State indicators used in calculation. Additionally, the survey results showed that the best predictor variable was unemployment, followed by the rest of the model's variables but with continuously declining significance.
\end{abstract}

Keywords: Fatal Accidents, Measurement, Variable, Labour Relations

\section{Introduction}

Work is considered as a systematized set of activities that lead to achieving the sought results. On the other hand, labour relations are all those relations that develop within organisations, with emphasis on the relations that arise as mandatory actions of employers to employees. These mandatory actions, even if not a formal requirement for organisations, in the formal sense of the term, are, however, necessary for ensuring their proper operation and maintaining a high level of employee satisfaction. One such action is the existence and maintenance of good and safe working conditions, an action that, according to Herzberg, concerns the satisfaction of hygiene factors or maintenance factors in the context of creating conditions for the effective organisation and operation of an organization. The absence of these factors causes organisational and operational problems, while their presence helps ensure the necessary balance in the operation of organisations, in the sense that they meet the established standards for their organisation and operation [12]. Ensuring maintenance or hygiene factors is mainly associated with the operation of the organisation as a whole and is the subject of study of labour relations.

Accidents, musculoskeletal disorders and stress at work are fundamental concerns of European Business as concerns Health and Safety at Work (HSW), [10]. According to the International Labour Organization [14], an occupational accident is a sudden event due to a violent incident, causing death or damage to the health or physical integrity of a person insured and occurring during the performance of work, or on the occasion of it and not caused by the insured person.

Since the dawn of humanity, man has strived to satisfy his life's needs through actions. All these actions as they are subject to the law of probability, can lead to minor or large accidents. The severity of the accidents and the probability of a slight or a fatal injury are not known in advance and the potential number or presentence of accidents is zero [25]. However, occupational accidents are 
inevitable incidents that create a huge number of problems. From an economic point of view, occupational accidents lead to reduction of production and productivity, raise accident premiums and pensions benefits, causing a huge increase in cost both for enterprises and for the National Economy. On the other hand, the death of an employee or his temporary or permanent injury due to an occupational accident can cause a series of effects in his general social environment [3]. According to the report of the European Occupational Safety and Health Organisation EU-OSHA, almost 5,000,000 accidents occur every day, which results in a three-day work absence, while $6 \%$ of accidents lead to a three-month absence from work. The yearly loss in work days reaches 146 million euro, while direct indemnification costs are about 20 billion euro. Most of these accidents are falls and car accidents. Furthermore, according to the International Labour Organization [14] more than 159,000 EU employers die every year of occupational diseases. Taking in account these numbers, it is estimated that an employee dies due to work-related causes every 3.5 minutes. Even though great progress has been accomplished as concerns Health and Safety, this enormous number of deaths, injuries and occupational diseases is still unacceptable high [9]. In the last 50 years of the past century, almost 500,000 fatal injuries were reported. Every year, 10 million employees were victims of occupational accidents and working diseases. In the same period, about 2,000,000 accidents were recorded in Greece with a huge social impact and great economic costs [18]. Globally, despite all the efforts to improve working conditions, workrelated deaths are estimated to reach about 2 million, while 330 million occupational accidents are added to each year's review.

The main purpose of this survey is to investigate the possible relation between fatal injuries and different macroeconomic measures or other State indicators. Namely if they are significant elements for the numerical prediction of fatal injuries occurring in a country, the unemployment rate, the industrial production rate, the net Per capita income, the total expenditure and other measures, which will be analyzed below. At the same time, we investigate the verification of the degree of influence of all the model's variables as concerns their use.

The paper is structured as follows: After the introductory first part, in the second part, we proceed to examine what should be considered as key factors in our regression analysis. The third section discusses the research methodology. The fourth section presents the research findings. The fifth section discusses the study limitations and finally concludes with a summary of findings and serves as a motive for further research.

\subsection{Factors that Should Be Considered}

Developments in labour relations are the inevitable product of corresponding changes in the economy, the institutional framework and the operation of political and social institutions, as the national labour relations system is composed of and formed on the basis of the interaction and confrontation of different social stakeholders, such as trade unions, employers' associations and policy instruments for employment and the labour market [17]. The organisational aspects of work, which are expressed through the framework of Hygiene and Safety conditions and its natural environment, influence the manner and extent to which occupational diseases and work accidents occur.

There are also and many other factors that, because of the rapid changes in the nature of work, affect either the prevention or the occurrence of occupational accidents [7] as above:

- Changes in business management through the unification and globalization of markets [4].

- Free trade, personalization of markets, locking of big State Enterprises and the diminution of organizations in both the private and public sector [11].

- Increase of the number of subcontractors, changes in the traditional industry and conversion of the economy [2].

- Increase of telecommuting, work at home, changes in working times, course and pressure of work [27].

- Changes in the work market with simultaneous increase of part-time jobs, temporally employment [16] and self-employment [26], female employment and ageing of the work force $[27,21]$.

Recent changes have a huge impact on how Health and Safety at Work (HSW) is managed [1]. The new technological developments can minimise old hazards but also can easily create new ones. For example, subcontracting can easily lead to confusion about who is responsible for the implementation of HSW [7]. The size of enterprises must be seriously taken into account, as small businesses usually do not have the elementary organisation structure for the affective prevention of occupational accidents [21]. Over the years, the anticipation and prevention of occupational accidents has definitely proven a successful process. Principles, models and theoretical approaches have lead to the creation of actions for accident prevention and to the adoption of effective procedures. However, these approaches change over the decades due to changes in needs and work processes [24].

The EU's approach to the prevention of occupational accidents consists of:

- avoiding risks;

- $\quad$ evaluating risks that cannot be avoided;

- $\quad$ combating the risks at source;

- $\quad$ adapting the work to the individual, especially the design of workplaces, the choice of work equipment and the choice of working and production methods, with a view, in particular, to alleviating monotonous work and work at a predetermined work-rate and to reduce their effect on health;

- $\quad$ adapting to technical progress;

- replacing dangerous items with non-dangerous or less dangerous; 
- developing a coherent overall prevention policy covering technology [10]

In 1995, the European Foundation published the European health and safety database (HASTE) with descriptive summaries of systems for monitoring health and safety at work. The report included $212 \mathrm{OSH}$ monitoring systems, classified into 15 types, from 15 European countries, Norway, the Czech Republic, the European Union and the World Health Organisation. Table 1, below, lists the types of systems included in the HASTE report.

Table 1. OSH systems described in the EFILWC-HASTE report (1995).

\begin{tabular}{lc}
\hline Type of system & $\begin{array}{c}\text { Number of } \\
\text { descriptions }\end{array}$ \\
\hline Occupational accident registers & 31 \\
Occupational disease registers & 25 \\
Exposure registers (environmental and biological) & 34 \\
Product and substance registers & 8 \\
Cancer registers & 4 \\
Birth, death and mortality registers & 8 \\
Ill-health absenteeism registers & 4 \\
Preventive service activity registers & 18 \\
General health surveys & 12 \\
Quality of working life surveys & 30 \\
Working time and work organisation surveys & 10 \\
Labour force surveys & 13 \\
Demographic and economic censuses & 4 \\
Documentation centres & 4 \\
Others & 11 \\
Total number of systems described & $212[8]$ \\
\hline
\end{tabular}

Table 1 shows that the factors taken into consideration included demographic and economic measures, information about production, general data about health expenditure, working hours, information of the workforce etc.

European statistics on accidents at work (ESAW) cover all accidents that result in an absence of at least four calendar days. Data as above were used to prepare various categories:

- Population and households;

- employment:

- employment rates,

- self-employment,

- employees,

- temporary employees,

- part-time employment,

- those in employment having a second job,

- $\quad$ working time;

- unemployment;

- inactivity [8]

The report (COM (2001) 619 final, 30.10.2001) presents the main outcome of the Commission's second year of work on structural indicators. Some new indicators were included and others had to be dropped. The new list includes 36 indicators in the following six fields for the Synthesis report 2002:

1. general economic background

2. employment

3. innovation and research

4. economic reform

5. social cohesion

6. environment

Employment includes the following six indicators:

1. employment rate

2. employment rate of older workers

3. gender pay gap

4. tax rate on low-wage earners

5. lifelong learning

6. accidents at work [8].

\section{Research Methodology}

The research was carried out using multiple linear regressions with the help of the SPSS ver. 19 statistical package and a stepwise method. Through multiple regression, we will try to predict the value of the independent variable, which arises from the values of the set of independent variables. Therefore, through this retrograde equation, if we have at our disposal the values of the independent variables, we will draw in each case the value of the dependent variable. The independent variables used to forecast the dependent variable in the regression came from macro-economic measures and other State rates, from the Organisation for Economic Co-operation and Development, [22] retrieved on 9-6-2010 and again from the same organisation (Organisation for Economic Cooperation and Development) [23] retrieved on 2-10-2011 and they are:

Table 2. Dependent variables.

\begin{tabular}{lc}
\hline Description & $\begin{array}{c}\text { name in the } \\
\text { model }\end{array}$ \\
\hline Harmonized Unemployment Rate & unemloy \\
Industrial Production Rate & industry \\
Total Central Government Debt (\% GDP) & ellimma \\
Relative Unit Labour Manufacturing Cost & ind_cost \\
Retention Ratio & retention \\
General Production & production \\
Real Hourly Minimum Wages in US \$ & wage \\
Net National Income per Head in US \% & net_income \\
Average Hours Worked per Person Yearly & work_hour \\
\hline
\end{tabular}

The dependent variable (fat_inj), numerical type used represents the rate of fatal injuries per 100,000 workers insured derived from the International Labour Organisation [15] website and particularly from its statistical office (LABORSTA). We aimed for the maximum number of cases. Thus, with data we collected on 18-8-2010 as the number of fatal accidents, we attempted over time to include all the countries that publish statistical data on the 
ILOs' website and especially in the category fatal injuries per 100,000 workers insured. The reason for using this measure (fatal injuries) for the dependent variable of the equations is that it accumulates all the advantages that demand multiple linear regression for importing analysis: a) Its numerical type, b) Its uncontested measure (there is no little- less- middle in this category), c) The possible choice of another category of occupational accidents is liable to the subjectivity of the estimation method in different countries. For example, some countries exclude all car accidents from the occupational category, even if jobrelated in many cases [8], d) It obtains the maximum number of cases for entry in regression model (91). Therefore, for the fatal injury and annual data available for each country, we formed table 3 , which in fact shows the 91 numerical cases of the dependent variable (beside each country and date we insert the case number). In cases of gaps or omissions of dates or countries, the reason is the lack of data. The data used were obtained from the International Labour Organisation [15] on 18-8-2010 and since then the service did not publish similar updated data.

Table 3. Case numbers

\begin{tabular}{|c|c|c|}
\hline Australia 2007 c.1 & Ireland 2006 c.32 & Slovakia 2000 c.63 \\
\hline Austria 2007 c. 2 & Slovakia 2006 c.33 & Belgium 2008 c.64 \\
\hline Canada 2007 c. 3 & Australia 2005 c. 34 & Belgium 2007 c. 65 \\
\hline Czech Rep. 2007 c. 4 & Finland 2005 c. 35 & Slovenia 2007 c. 66 \\
\hline Finland 2007 c. 5 & Ireland 2005 c. 36 & Belgium 2006 c. 67 \\
\hline France 2007 c. 6 & Mexico 2005 c. 37 & Slovenia 2006 c. 67 \\
\hline Germany 2007 c. 7 & Slovakia 2005 c. 38 & Belgium 2005 c.69 \\
\hline Hungary 2007 c. 8 & Australia 2004 c. 39 & Slovenia 2005 c. 70 \\
\hline Ireland 2007 c. 9 & Finland 2004 c. 40 & Turkey 2006 c.71 \\
\hline Italy 2007 c. 10 & Ireland 2005 c. 41 & Turkey 2005 c. 72 \\
\hline Mexico 2007 c. 11 & Mexico 2004 c. 42 & Belgium 2004 c. 73 \\
\hline Norway 2007 c. 12 & Slovakia 2004 c. 43 & Luxembourg 2004 c.74 \\
\hline Poland 2007 c. 13 & Australia 2003 c.44 & Slovenia 2004 c. 75 \\
\hline Portugal 2007 c. 14 & Finland 2003 c. 45 & Turkey 2004 c.76 \\
\hline Slovakia 2007 c. 15 & Ireland 2003 c. 46 & Belgium 2003 c.77 \\
\hline Spain 2007 c. 16 & Mexico 2003 c.47 & Luxembourg 2003 c. 78 \\
\hline Sweden 2007 c. 17 & Slovakia 2003 c.48 & Slovenia 2003 c.79 \\
\hline Switzerland 2007 c. 18 & Australia 2002 c.49 & Belgium 2002 c. 80 \\
\hline USA 2007 c. 19 & Finland 2002 c. 2002 & Luxembourg 2002 c. 81 \\
\hline Australia 2008 c. 20 & Ireland 2002 c. 51 & Slovenia 2002 c. 82 \\
\hline Canada 2008 c. 21 & Mexico 2002 c. 52 & Turkey 2002 c. 83 \\
\hline Czech Rep. 2008 c.22 & Slovakia 2002 c. 53 & Belgium 2001 c. 84 \\
\hline Germany 2008 c. 23 & Australia 2001 c.54 & Denmark 2001 c. 85 \\
\hline Ireland 2008 c. 24 & Finland 2001 c.55 & Slovenia 2001 c. 86 \\
\hline Mexico 2008 c. 25 & Ireland 2001 c. 56 & Belgium 2000 c. 87 \\
\hline Norway 2008 c.26 & Mexico 2001 c.57 & Denmark 2000 c. 88 \\
\hline Poland 2008 c. 27 & Slovakia 2001 c. 58 & Luxembourg 2000 c.89 \\
\hline Slovakia 2008 c. 28 & Australia 2000 c.59 & Slovenia 2000 c. 90 \\
\hline Spain 2008 c. 29 & Finland 2000 c. 60 & Turkey 2001 c.91 \\
\hline Australia 2006 c.30 & Ireland 2000 c. 61 & \\
\hline Finland 2006 c31 & Mexico 2000 c.62 & \\
\hline
\end{tabular}

As concerns the independent variable derived from the Organization for Economic Cooperation and Development $[22,23]$ and its StatExtract service, we chose this as it had data for the years and countries that the particular variable includes. Furthermore, all of them satisfy the measuring principle in numerical or ordinal type. There is also an independence of cases in the sense that entering one case does not affect the participation of any other.

\section{Analysis of Results - Discussion}

As known, the cases in the model are 91, considered a satisfactory number for the research needs. Coakes and Stead [5] consider that the number of cases should be at least five times the number of variables (predictors). Furthermore, Field [13] supports that for one reliable regression model we need 10 observations (cases) per independent variable.

Table 4. Descriptive Statistics.

\begin{tabular}{lccc}
\hline & Mean & Std. Deviation & N \\
\hline fat_inj & 4,5336 & 2,62540 & 42 \\
unemloy & 6,9012 & 3,67042 & 42 \\
industry & 2,6167 & 4,34337 & 42 \\
ellimma & 35,8095 & 27,35649 & 42 \\
ind_cost & 100,2548 & 6,65829 & 42 \\
retention & 86,8598 & 7,30349 & 42 \\
production & 104,0929 & 7,94077 & 42 \\
wage & 6,1233 & 3,92145 & 42 \\
net_income & 24044,1571 & 9251,14352 & 42 \\
work_hour & 1731,4524 & 135,08249 & 42 \\
\hline
\end{tabular}

In table 4 (Descriptive Statistics), we observe than from 91 cases, 42 were finally selected for the regression due to missing values via the Listwise Method [20]. We also observe that the mean of the independent variable is 4, 5336 , which represents the average grade of fatal injuries from the 42 cases in the sample.

Table 5. Correlations.

\begin{tabular}{cccc}
\hline $\begin{array}{c}\text { Pearson Correlation } \\
\text { fat_inj }\end{array}$ & $\mathbf{1 , 0 0 0}$ & $\begin{array}{c}\text { Sig. (1-tailed) } \\
\text { fat_inj }\end{array}$ & - \\
\hline unemloy & $-0,091$ & unemloy & 0,284 \\
industry & $-0,045$ & industry & 0,389 \\
ellimma & 0,222 & ellimma & 0,078 \\
ind_cost & $-0,122$ & ind_cost & 0,220 \\
retention & 0,083 & retention & 0,301 \\
production & $-0,080$ & production & 0,308 \\
wage & $-0,566$ & wage & 0,000 \\
net_income & $-0,580$ & net_income & 0,000 \\
work_hour & 0,289 & work_hour & 0,032 \\
\hline
\end{tabular}


In Table 5 (Correlations) in $2^{\text {nd }}$ column $10^{\text {th }}$ line (Pearson Correlation), we can see that that the highest price of the Pearson indicator belongs to the predictor work hour with Pearson $\mathrm{r}=28.9 \%$ followed by the variable ellimma (Pearson $\mathrm{r}=22.2 \%$ ) while the lowest level of crosscorrelation with the dependent variable is presented by the independent variable production (Pearson $\mathrm{r}=-8 \%$ ).

The $4^{\text {th }}$ column reveals that the variables wages, net income and work hours have high cross-correlation with the dependent one because the observed level of statistical significance is sign. (1-tailed) $\leq 5 \%$, while in rest of the predictors are poorly correlated. This is not a cause of concern, because this phase simply describes simple correlations and does not describe the behaviour of the 9 predictors and their influence on the regression model.
Table 6. Variables Entered/Removed ${ }^{a}$

\begin{tabular}{ccl}
\hline Model & Variables Entered & Method \\
\hline 1 & net-income & Stepwise(Criteria: \\
2 & unemloy & Probability-of- F-to- \\
3 & production & enter $<=0,50$, \\
4 & ellimma & Probability-of-F-to- \\
5 & wage & remove $>=0,100$ \\
\hline
\end{tabular}

Table 6 shows which predictors were entered and removed from the model using the Stepwise Method, in which time and with which criteria. Therefore, we observe that 5 predictors from 9 were chosen.

Table 7. Model summary

\begin{tabular}{ccccccc}
\hline Model & R & R Square & $\begin{array}{c}\text { Adjusted } \\
\text { R Square }\end{array}$ & $\begin{array}{c}\text { R Square } \\
\text { Change }\end{array}$ & $\begin{array}{c}\text { Sig. F } \\
\text { Change }\end{array}$ & $\begin{array}{c}\text { Durbin } \\
\text { Watson }\end{array}$ \\
\hline 1 & $0,580^{\mathrm{a}}$ & 0,336 & 0,319 & 0,336 & 0,000 & \\
2 & $0,669^{\mathrm{b}}$ & 0,448 & 0,420 & 0,112 & 0,008 \\
3 & $0,745^{\mathrm{c}}$ & 0,555 & 0,519 & 0,106 & 0,005 & \\
4 & $0,821^{\mathrm{d}}$ & 0,674 & 0,638 & 0,119 & 0,001 & \\
5 & $0,862^{\mathrm{e}}$ & 0,744 & 0,708 & 0,070 & 0,003 & 2,054 \\
\hline
\end{tabular}

a. Predictors: (Constant), net income

b. Predictors: (Constant), net_income, unemloy

c. Predictors: (Constant), net_income, unemloy, production

d. Predictors: (Constant), net_income, unemloy, production, ellimma

e. Predictors: (Constant), net_income, unemloy, production, ellimma, wage

f. Dependent Variable: fat-inj

Table 7 presents a summary of the regression model indicators, using the Stepwise method, which appears to develop in 5 phases, i.e. the same number as the independent variables entered. In column 3, which shows the multiple determination factor R Square (Goodness of fit), we observe that after the insertion of 5 predictors (model 5), $74.4 \%$ of the total dissemination of the dependent variable fat inj is explained, which is considered high for social sciences [19].
The factor $\mathrm{R}$ of multiple cross-correlation (column 2) with $86.2 \%$, shows high cross-correlation between observed and forecast prices of the dependent variable. The adapted determination factor in column 4 (Adjusted R Square), has high predictive value $(70.8 \%)$. In addition, this is also confirmed by the ratio $\mathrm{n} / \mathrm{k}=91: 9=10,1>5$ ( $\mathrm{n}=$ cases, $\mathrm{k}=$ independent variables). In column 5 , with indicator $\mathrm{R}$ Square Change, we observe that in model 1, where only net income was the inserted variable, the rate was $33.6 \%$. The insertion of the second predictor, unemloy, offered $11.2 \%$ more, while the other remaining variables contributed with similar percentages. Finally, column 6, which shows the statistical importance levels Sig. f Change, reveals that all predictors are equal or greater than the criterion set, from the beginning, for insertion in model $(0$, 0005).

Table 8. Coefficients ${ }^{a}$

\begin{tabular}{|c|c|c|c|c|c|c|}
\hline \multirow[t]{2}{*}{ Model } & & \multicolumn{2}{|c|}{$\begin{array}{l}\text { Unstandardized } \\
\text { Coefficients }\end{array}$} & \multirow[b]{2}{*}{$\mathrm{T}$} & \multicolumn{2}{|c|}{$\begin{array}{l}\text { Collinearity } \\
\text { Statistics }\end{array}$} \\
\hline & & B & Std. Error & & Tolerance & VIF \\
\hline \multirow{6}{*}{6} & (Constant) & 25,270 & 3,541 & 7,136 & & \\
\hline & net_income & 0,000 & 0,000 & $-2,250$ & 0,219 & 4,569 \\
\hline & unemloy & $-0,397$ & 0,069 & $-5,720$ & 0,755 & 1,324 \\
\hline & production & $-0,140$ & 0,030 & $-4,623$ & 0,847 & 1,180 \\
\hline & ellimma & 0,046 & 0,009 & 4,959 & 0,756 & 1,323 \\
\hline & wage & $-0,375$ & 0,119 & $-3,140$ & 0,224 & 4,471 \\
\hline
\end{tabular}

a. Dependent Variable: fat-inj 
Column B contains all the information for the 6 retrograde equation variables also including the constant term. Thus, the retrograde equation formed is: fat_inj $=[(0)$. (net_income $)]+[(-0,397) . \quad$ (unemloy) $]+[(-0,140)$. (production) $]+[(0,046)$. (ellimma) $]+[(-0,375)$.(wage $)]$ $=25,27$.

We observe that net income variable has a zero effect, maybe because of its high absolute value as compared with the other predictors. Only the ellimma predictor has a positive effect while the rest of the variables (unemloy, production, wage) have a negative influence on the dependent fat inj. However, the best predictor variable is the one with the higher values in the column with $t$ values. Thus, at the top we have the best predictor which in our case is the unemloy predictor as it has the largest absolute $t$ value $(|5,720|)=-5,720$. Thereafter there follow with degreasing values - but always important for our equation the predictors: ellimma with absolute $\mathrm{t}$ value $(|4,959|)$, production $(|4,623|)$, the wage $(|3,140|)$ and the predictor net_income $(|2,250|)$ with increasingly smaller but not less than 2 values.

\section{Control of Admissions}

\subsection{Independent Control Admission}

The independent control admission is satisfied via the Durbin-Watson statistical indicator (table 7). As the indicator has a score between 1.5 and 2.5 (in our cases 2.054) the observation of independence is ensured. Apart from this, the number of observations (91) is a multiple of the number of predictors.

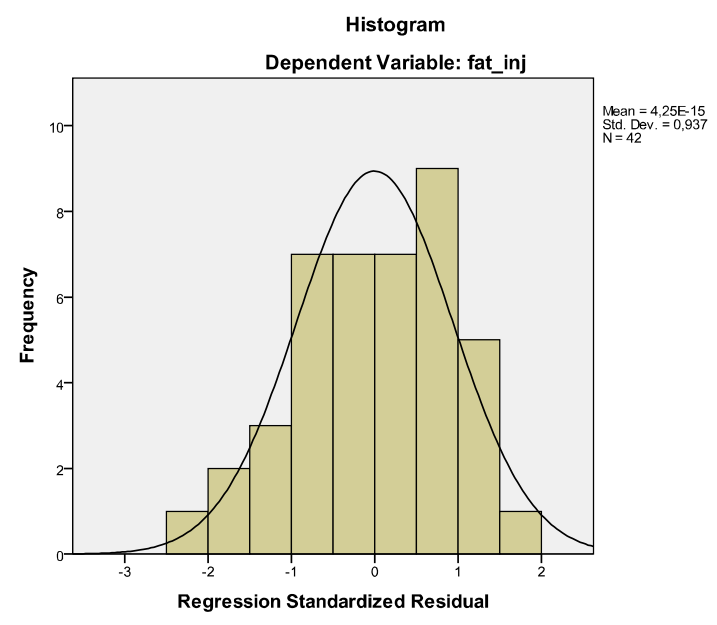

Figure 1.

\subsection{Control of Distribution Regularity}

One of the main research concerns during the regression procedure is the possible violent interruption of regularity. Figure 1 shows that standardized Residuals follow the regular distribution with a Gauss Bell to have symmetry and normality in how values are distributed.

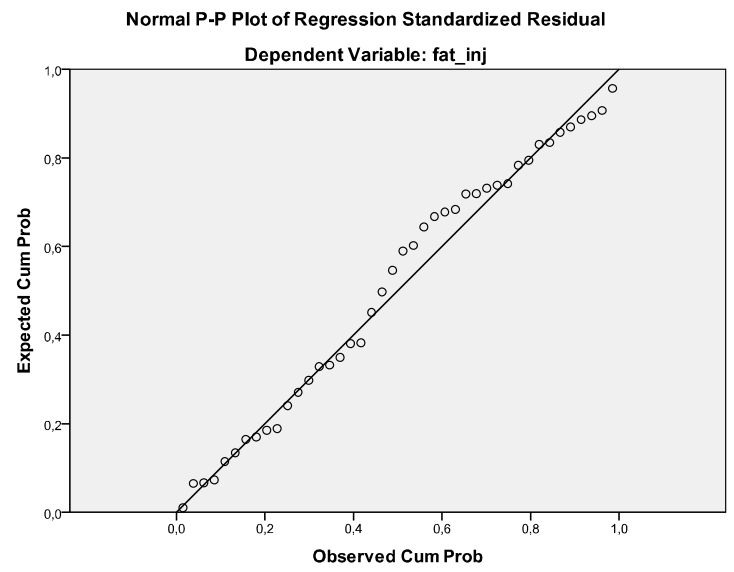

Figure 2.

Moreover in figure 2, Normal P-P plot of Regression Standardized Residual, where the vertical axis has the cumulative frequencies of the dependents' predictor expected values, while the horizontal presents the cumulative frequencies of the dependents' predictor observed values, we note that, because the figure dots are very near the line bisecting the $\mathrm{x}$ and $\mathrm{y}$ axes, we have a very clear indication of the approximate normality of our regression.

\subsection{Control of Linearity and Disseminate Equality Admission}

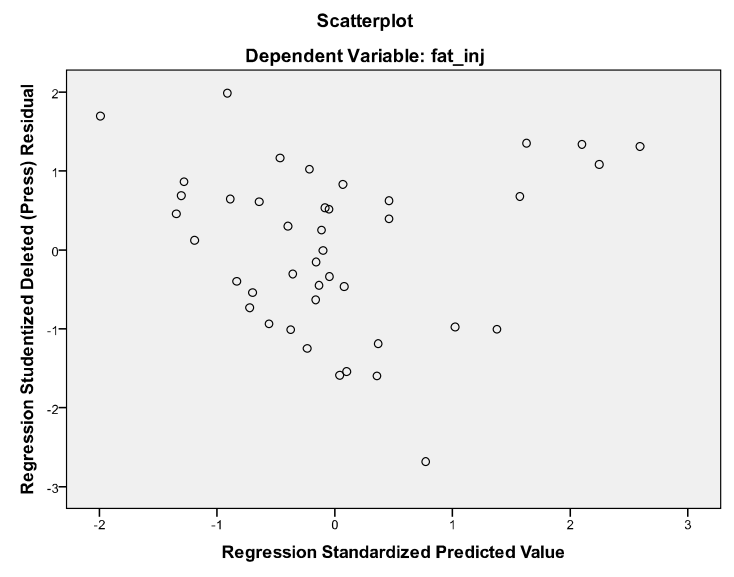

Figure 3.

The Scatter Plot (Figure 3), which shows a scatter plot of Deleted Residuals against Predicted Values, satisfies the linearity and disseminates equality admissions, with patterns and systematic clustering absence. 


\subsection{Multi- Linear Evasion Control}

Table 9. Collinearity Diagnostics.

\begin{tabular}{|c|c|c|c|c|c|c|c|c|c|}
\hline \multirow{2}{*}{ Mod. } & \multirow{2}{*}{ Dim } & \multirow{2}{*}{$\begin{array}{l}\text { Eigen } \\
\text { Value }\end{array}$} & \multirow{2}{*}{$\begin{array}{c}\text { Condition } \\
\text { Index }\end{array}$} & \multicolumn{6}{|c|}{ Variance Proportion } \\
\hline & & & & Constant & net_income & Unemloy & production & ellimma & Wage \\
\hline \multirow{6}{*}{5} & 1 & 5,183 & 1,000 & 0,00 & 0,00 & 0,00 & 0,00 & 0,01 & 0,00 \\
\hline & 2 & 0,444 & 3,415 & 0,00 & 0,01 & 0,10 & 0,00 & 0,14 & 0,05 \\
\hline & 3 & 0,258 & 4,482 & 0,00 & 0,00 & 0,10 & 0,00 & 0,65 & 0,02 \\
\hline & 4 & 0,093 & 7,461 & 0,01 & 0,00 & 0,74 & 0,01 & 0,05 & 0,12 \\
\hline & 5 & 0,020 & 16,175 & 0,00 & 0,89 & 0,00 & 0,02 & 0,14 & 0,81 \\
\hline & 6 & 0,002 & 49,077 & 0,99 & 0,10 & 0,06 & 0,97 & 0,02 & 0,00 \\
\hline
\end{tabular}

In table 9 (Collinearity Diagnostics) and in column of eigenvalues of covariance matrix, we observe that none of the variables is zero $(0)$ and that only the index of the variable wage approaches dangerously $(0,002)$.

Additionally in Table 8 (Coefficients) where Tolerance Factor is analyzed, we observe that it has values from 0 to 1 . When an independent variable has a tolerance near 1 , it means that only a very small percentage of its distribution can be explained by other independent variables, which happens exactly in our case. Also in the same table (8) and for the variance inflation Factor VIF, when it does not exceed 10 there is no problem of Multi-linear evasion [19], which also exists in our analysis.

\section{Conclusion and Suggestions for Further Research}

The basic aim of this research was to investigate the relation between fatal injuries and different macroeconomic measures or other State indicators. The research aim was achieved with the creation of a retrograde equation, presented in column B of table 8 (Coefficients), showing all the data of the 6 regression parameters. All variables in the equation affect the configuration of the dependent variable "fat_inj" (fatal injuries). Thus the predictor "net-income" (Net National Income per Capita in US \%) with zero inflation and the variable "ellimma" [Total Central Government Debt (\% GDP)] is the only one with a positive influence, while the rest (unemloy, production, and wage) have a negative effect on the dependent one. The second objective was to verify the degree of influence of all the model's variables, in which the values of used variables were counted via extraction and interpretation of the retrograde equation. However, based on the statistical importance levels, that correspond to the $t$ values of table 8 ., the best predictor variable is unemloy (Harmonized Unemployment Rate), followed by ellimma, production, wage and the predictor net_income. Even if the hierarchy is considered, [6] as more representative of variable value, it would nevertheless not be wise to interpret their numerical classification in an absolute way because of the reserve of $t$ prices theoretical approach.
The research has numerous restrictions. Findings ca not be generalised without verification. Thus, there is a need for more extensive research using another sample with the use of another kind of dependent variable and other independent variables. Also, research on the examination of each variable that influences output separately must be realized.

\section{References}

[1] Benach, J. "A new occupational health prevention for a new work environment: needs, principles and challenges", TUTB-Saltsa Working Without Limits Conference and Newsletter, No 15-16, pp.13-18, February 2001.

[2] Bullinger, H. J.. "The changing world of work: prospects and challenges for health and safety", Magazine of the European Agency for Safety and Health at Work, 2, 2000, pp. 51-58.

[3] Branis, S. "Statistics for Occupational Accidents in Greece", Athens: Greek Institute for Health and Safety at Work, 1998, pp. $8-28$.

[4] Clifton, R. "The consequences of new enterprise structures", Magazine of the European Agency for Safety and Health at Work, No 2, 2000, pp.1-22.

[5] Coakes, S. J. and Steed, L.G. "SPSS without Anguish", New York: John Wiley and Sons Inc, 1999, pp. 5-32.

[6] Dafermos, V.."Social statistics with SPSS", Thessalinica: Publications Ziti, 2005, pp.8-22.

[7] European Agency for Safety and Health at Work. "New trends in accident prevention due to the changing world of work", Luxembourg: Office for Official Publications of the European Communities, pp.1-12, 2002.

[8] European Agency for Safety and Health at Work. "A review and analysis of a selection of $\mathrm{OSH}$ monitoring systems", Printed in Belgium: Office for Official Publications of the European Communities, pp.3-8, 2003.

[9] European Agency for Safety and Health at Work. "Building in Safety - Prevention of risks in construction -in practice, Printed in Spain: Office for Official Publications of the European Communities, pp. 4-11, 2004.

[10] European Agency for Safety and Health at Work. "European Research for the new and resurgent business risks, Printed in 
8 N. E. Giovanis and G. A. Drogalas: Labor Relations and Working Conditions. Determinants using Macroeconomic Indicators: A Quantitative Research

Belgium : Office for Official Publications of the European Communities, pp. 8-25, 2010.

[11] European Agency for Safety and Health at Work. "Drivers and barriers for psychosocial risk management: An analysis of the findings of the European Survey of Enterprises on New and Emerging Risks (ESENER)", Luxembourg: Publications Office of the European Union, pp. 18-31, 2012.

[12] Fanariotis, P. "Labour Relations, 2nd Edition", Athens: Stamoulis SA Publications, 2004, pp. 35-36.

[13] Field, A. "Discovering Statistics Using SPSS for Windows. Advanced Techniques for the Beginner", Beverly Hills CA: Sage publications, 2000, pp.33-44.

[14] International Labour Organisation. "General Survey concerning the Occupational Safety and Health Convention, 1981 (No. 155), the Occupational Safety and Health Recommendation, 1981 (No. 164), and the Protocol of 2002 to the Occupational Safety and Health Convention, 1981," Geneva, Switzerland, Office of Official publication of ILO, pp. 22-137, 2009.

[15] International Labour Organisation. (2010, August, 18). Statistics and Databases, Retrieved from the Database of Labour Statistics, LABORSTA website: http://ladorsta.ilo.org/STP/guest.

[16] Johansson, A. "Work organisation in an ageing Europe", Magazine of the European Agency for Safety and Health at Work, No 2, 2000, pp.23-41.

[17] Labour Institute . " GSEE-ADEDY Labour Relations in Europe and Greece: Annual Report 2009”, Athens: National Printing Office, 2009, pp.22-78.

[18] Makropoulos, B. "Note of the Editorial Board", Journal of the Greek Institute for Health and Safety at Work, Vol.1, 2000, p 1 .
[19] Myers, R. "Classical and Modern Regression with Applications. ( $2^{\text {nd }}$ ed.)”, Boston, MA: Duxbury Press, 1990, pp.12-90.

[20] Nurosis, M. "SPSS 11.0 Guide to Data Analysis", Englewood Cliffs:Prentice Hill, 2002, pp. 9-89.

[21] Op De Beeck, R., Hermans, V., De Broeck, V., Willems, F. "Study on accidents at work and employability", European Agency for Health and Safety Work, Luxembourg: Publications Office of the European Union, 2001, pp. 7-21.

[22] Organisation for Economic Co-operation and Development. "Statistical Extracts. Retrieved from the Complete Database Available via OECD's Library", website: http://stats.oecd.org/Index.aspx?DatasetCode=PDYGTH, access (2010, September, 9).

[23] Organisation for Economic Co-operation and Development. "Statistical Extracts. Retrieved from the Complete Database Available via OECD's Library", website: http://stats.oecd.org/Index.aspx?DatasetCode=PDYGTH, access (2010, October, 2).

[24] Saari, J. "Accident prevention today", Magazine of the European Agency for Safety and Health at Work, No 4, 2001, pp.22-44.

[25] Targouzidis, A. "The Phenomenon of Occupational accident: Accidents' Models, Human Failure, Risk Perception", Athens: Greek Institute for Health and Safety at Work, 2007, pp. 5-15.

[26] Van Eijnatten, F. M. " From intensive to sustainable work systems: the quest for a new paradigm of work', TUTBSaltsa Working Without Limits", Conference and Newsletter, No 15-16, pp. 4-17, February 2001.

[27] Work life. "Work force diversity in Europe: immigration and ageing as policy challenges", National Institute for Working Life, 2000, pp.9-51 